Glansectomy with split-thickness skin graft reconstruction for penile cancer

\title{
Clinical outcomes of glansectomy with split-thickness skin graft reconstruction for localized penile cancer
}

\author{
Ben B. Beech; David W. Chapman; Keith F. Rourke \\ Division of Urology, Department of Surgery, University of Alberta, Edmonton, AB, Canada
}

Cite as: Can Urol Assoc J 2020 May 12; Epub ahead of print.

http://dx.doi.org/10.5489/cuaj.6277

Published online May 12, 2020

$* * *$

\begin{abstract}
Introduction: Penectomy as the traditional surgical treatment of penile cancer, has substantial adverse functional and psychological impact. Glansectomy with split thickness skin graft (STSG) reconstruction aims to provide curative resection while maximizing functional outcomes, and minimizing psychological harm. We describe our outcomes of glansectomy with STSG reconstruction for penile cancer in a Canadian setting.
\end{abstract}

Methods: We identified patients undergoing glansectomy with STSG genital reconstruction for squamous cell carcinoma of the penis from July 2006 to July 2019 at a single center. Patients undergoing glansectomy for reasons other than penile cancer were excluded. We collected clinical and pathological data, including patient demographics, 90-day complications, positive margin rate, local recurrence rate, disease-specific survival, and functional outcomes. Descriptive statistics were used to characterize our cohort and to examine outcomes.

Results: Twelve men met study criteria with a median age of 62 years. Seven patients had failed prior treatment. The 90 -day complication rate (Clavien $>2$ ) was $0 \%$ and graft take was excellent in all cases. The positive margins rate was $16.7 \%(n=2)$. Local recurrence occurred in two patients $(16.7 \%)$, one of whom underwent a repeat organ-sparing surgery for salvage, while the other underwent radical penectomy for high-risk pathological features. Disease-free survival at a median followup of 14 months was 91.7\% (11/12). Standing voiding and erectile function, as well as satisfactory cosmesis were preserved in all patients.

Conclusions: Glansectomy with STSG reconstruction is a safe and effective treatment for men with localized penile cancer with simultaneous preservation of cosmesis, as well as urinary and sexual function. 


\section{Glansectomy with split-thickness skin graft reconstruction for penile cancer}

\section{Introduction}

While penile cancer is an uncommon disease in the developed world, it is associated with devastating morbidity and mortality rates. ${ }^{1-3}$ Risk factors for squamous cell carcinoma of the penis include phimosis, smoking, obesity, low socioeconomic status and HPV infection. ${ }^{1,4}$ The vast majority of penile caners involve the glans and/or the prepuce..$^{5-9}$ Despite this, surgical treatment has traditionally involved partial or total penectomy, in order to obtain a somewhat dogmatic $2 \mathrm{~cm}$ wide margin. This resulted in significant functional and psychological impacts, specifically urinary and sexual function, as well as body image. ${ }^{10-14}$ Evidence now suggests that smaller surgical margins are oncologically safe. ${ }^{15,16}$ This has led to the development of organ sparing surgery (OSS), which attempts to provide curative resection, combined with reconstruction to maximize functional outcomes, and minimize psychological harm. ${ }^{11,17-21}$

The OSS approach achieves improved functional outcomes for patients compared to more radical techniques but may be associated with increased rates of local recurrence (LR). ${ }^{11,21-}$ ${ }^{25}$ However, in men with low risk penile cancer, LR is typically salvageable with repeat resection, and without impacting mortality. ${ }^{20,26-28}$ In fact, repeat OSS is often possible. ${ }^{29,30}$

Many different techniques for OSS have been developed including laser therapies, glans resurfacing, and glansectomy with split thickness skin graft (STSG) reconstruction. ${ }^{31-33}$ Despite these techniques, many men in Canada do not receive OSS, even when appropriate candidates. ${ }^{34}$ We report our outcomes of glansectomy with STSG reconstruction of a neoglans, in the setting of localized squamous cell carcinoma of the penis.

\section{Methods}

We identified all men undergoing STSG genital reconstruction from July $1^{\text {st }} 2006$ through to July $20^{\text {th }} 2019$ with a single surgeon. We excluded those patients who underwent the procedure for reasons other than penile cancer (such as chronic lymphedema or liberation of buried penis). In all cases, complete glansectomy was performed by initial circumferential dissection along the plane between Darto's and Buck's fascia, and then mobilization of the glans off of the corporal body tips, dissecting between the tunica albuginea and Buck's fascia. This was followed by the use of a medium thickness $\left(15 / 1000^{\text {th }}\right)$ STSG (harvested from the upper thigh) in order to reconstruct a neo-glans, as described by Parnham (Figure 1). ${ }^{35}$ All components of the surgery were performed by a single surgeon (KFR). All patients had a bolster dressing in place for 5 days postoperatively and a urethral catheter for 2 weeks. Patient were subsequently assessed postoperatively at 4 weeks then every 3-6 months for 2 years and annually thereafter for another 3 years.

We collected both clinical and pathological data from the pre-, peri-, and post-operative settings. These included data on known risk factors for penile cancer (obesity, smoking history, lack of pediatric circumcision), prior treatments, 90-day complications, graft take, and functional (urinary and sexual) outcomes. Specifically, functional outcomes were recorded by the physician based on patient interviews at follow up visits and included standing voiding function, erectile 
function, acceptable cosmesis, and overall satisfaction. Further, cancer control outcomes (local recurrence, disease free survival), and pathologic outcomes (including stage, grade, and margin status) were also recorded. Descriptive statistics were utilized to characterize our cohort and to examine their outcomes.

\section{Results}

Between July 1, 2006 and July 20, 2019, we identified a total of 12 men who underwent glansectomy with STSG neo-glans reconstruction for penile cancer (Table 1: Patient demographics). Median follow up was 14 months (range 1 to 59) and median age at time of surgery was 62 years (range 32 to 85). All patients had a pathologic diagnosis of penile SCC (7 patients) or CIS (5 patients) prior to their definitive surgery . 7 patients had undergone prior treatment: topical therapy (5 patients), external beam radiotherapy (1 patient), and attempted Moh's micrographic surgery (1 patient). The majority of patients had risk factors for penile cancer including current or former smoking ( 8 of 12), obesity ( 8 of 12), and lack of pediatric circumcision (10 of 12).

The 90-day significant adverse event (SAE) rate was $0 \%$ (defined as Clavien-Dindo grade $>2$ ). Graft take was excellent in all cases when evaluated at the 4 -week post-operative visit, with no graft losses. All patients who had preserved erectile function pre-operatively maintained it post-operatively. Similarly, all patients maintained standing voiding function. 2 patients reported spraying of the urinary stream and 1 patient required subsequent meatal dilation with a durable result thus far. All patients reported acceptable cosmesis, as well as overall satisfaction (Table 2).

Pathology revealed no residual malignancy in 2 patients (pT0), pTis disease in 2 patients, pT1a in 5 patients, pT1b in 1 patient, and pT2 in 2 patients. The rates of low, moderate, and high grade disease were 2 patients, 5 patients, and 1 patient respectively. Positive surgical margins (PSM) were reported in 2 of 12 patients (see Table 3 ).

Local recurrence occurred in 2 patients at 2 and, 5 months respectively (Table 3). In 1 of these patients, a repeat organ sparing procedure was performed for salvage, and they remain without any evidence of disease at most recent follow up. However, the other patient did undergo a radical penectomy and creation of perineal urethrostomy due to high risk pathology (pT2, grade 2 lesion, with a positive deep margin). This patient also underwent bilateral inguinal and pelvic lymph node dissection confirming pN3 lymph node metastatic disease (5/13 nodes positive, bilateral inguinal zones, with positive extranodal extension). He then underwent adjuvant chemoradiotherapy. Despite this, at last follow up, he demonstrated radiological evidence of metastatic disease. Overall, the disease-free survival (DFS) was 91.7\% (11/12 patients). 


\section{Discussion}

Penile cancer is an uncommon disease in North America, but often has devastating morbidity and mortality. OSS attempts to minimize treatment associated morbidity, without compromising oncologic outcomes. Despite strong evidence in the literature, it continues to have limited uptake in Canadian practice. ${ }^{34}$ The reasons for this are uncertain and may in part be due to the overall rarity of the disease, leading to a lack of training in OSS techniques, as well as concerns over local recurrence, and the lack of Canadian guidelines.

Here, we present a single surgeon case series of OSS for men with clinically localized penile cancer at our center. Multiple known risk factors for penile cancer were prevalent in our cohort, including obesity, smoking, and lack of pediatric circumcision. ${ }^{1,4}$ Further, many of our patients had undergone prior treatment with a variety of modalities including topical therapies, radiotherapy, and Moh's micrographic surgery. These prior therapies did not seem to negatively impact our graft take or functional outcomes.

Regarding peri- and post-operative complications, we had excellent results with no SAEs $(\mathrm{CD}>2)$ within 90 days of surgery. Graft take was excellent in all cases with no instances of graft loss. One patient developed meatal stenosis requiring dilation, but there were otherwise no cases of repeat operation (outside of the 2 local recurrences discussed below). O'Kane et al., reported similar findings with no cases of graft loss and two patients requiring meatal dilatation in a series of 25 patients $(8 \%) .{ }^{36}$ Smith el al., reported revision surgery was required for functional complications in $4.2 \%$ of cases, while Parnham et al. reported revision surgery was required in $9 \%$ of cases. ${ }^{35,37}$ This is comparable to our revision surgery rate of $8.3 \%$.

From a functional perspective, we were able to achieve excellent outcomes, with preserved erectile function, standing to void, and acceptable cosmesis in all patients. 2 of the 12 patients $(16.7 \%)$ did report spraying with urination. These results compare favorably with other cohorts, with OSS consistently able to preserve urinary and sexual function in upwards of $80 \%$ of patients. ${ }^{11,17,21,36} \mathrm{We}$ also included acceptable cosmesis as an outcome of interest given the known psychological impact of penectomy via its effects on body image. ${ }^{11} \mathrm{We}$ believe that our excellent cosmetic outcomes should correlate with reduced psychological harm, although that was not measured in this study.

From an oncologic perspective, PSM occurred in 2 of 12 patients $(16.7 \%)$, as did LR. One of the patients with LR was able to be successfully salvaged with a repeat OSS procedure. Unfortunately, the other patient was found to have high risk disease despite initial biopsy demonstrating pT1a disease, and with clinically negative lymph nodes and a CT abdomen/pelvis and MRI pelvis revealing no signs of invasion into the corporal bodies, or of non-local disease prior to undergoing OSS. This patient then underwent radical penectomy as well as inguinal and pelvic lymph node dissection revealing $\mathrm{pN} 3$ disease, which was followed by adjuvant chemoradiotherapy. Despite this, he went on to develop metastatic disease. As such, our DFS 
was $91.7 \%$ (11 of 12 patient). Overall, our results are broadly similar to other published series on OSS, which accept a higher rate of PSM and LR, in exchange for decreased morbidity, and without sacrificing survival, given high rates of successful salvage. Reported rates of PSM in similar cohorts range from $9.8 \%$ to $14.5 \%$ while rates of LR range from $4 \%$ to $12.8 \%$, and DFS from 90 to $100 \%{ }^{35-38}$

There are also other published series which report on groups of men undergoing OSS for penile cancer with a mixture of techniques ranging from laser therapy, to wide local excision, glans resurfacing and of course glansectomy with STSG reconstruction as described herein. All report similarly high rates of erectile function preservation and standing voiding post-operatively but a wide variation in LR rates ranging from as low as $4 \%$ up to $42 \% .^{20,27,28,30,31,33,37,39,40}$ It is difficult to directly compare them with our cohort given the heterogenous treatment techniques and small cohort sizes.

Overall, our excellent functional outcomes, with low rates of revision surgery for meatal stenosis are comparable to the other reported series. However, our rates of PSM and LR are slightly higher, despite our cohort being, in general, men with lower risk disease. The reasons for these differences are unclear, but may in part be due to differences in surgical technique, and the small size of our cohort, which ultimately increases the impact of individual events.

Several limitations to this study exist, including the retrospective design, the small sample size and the lack of validated patient reported outcome measures. That being said, it is to our knowledge the only Canadian cohort of OSS for penile cancer in the literature. Most published penile cancer OSS series have come from Europe where this care is centralized to subspecialty referral centers. In North America, this model does not exist, limiting the experience with these techniques. Moving forward, a Canadian collaboration is necessary in order to improve the quality of care for Canadian men with penile cancer.

\section{Conclusions}

We present our series of men treated with organ sparing surgery for penile cancer, with glansectomy and STSG reconstruction of a neoglans. We have demonstrated that this is a viable technique in well selected men. From a functional perspective, urinary and sexual function are preserved. Organ sparing surgery should be discussed as an option, with all men who have localized and distal penile cancer. Moving forward, coordination is required among Canadian urologists to improve the quality of care received by men with this disease. Efforts should be made to collect and share data on a national scale in order to compare outcomes and advance best practices. 


\section{References}

1. Hakenberg OW, Compérat EM, Minhas S, et al. EAU guidelines on penile cancer: 2014 update. Eur Urol 2015;67:142-50.

2. Heller DS. Lesions and neoplasms of the penis: A review. J Low Genit Tract Dis 2016;20:107-11.

3. Siegel RL, Miller KD, Jemal A. Cancer statistics, 2016. CA Cancer J Clin 2016;66:7-30.

4. Douglawi A, Masterson TA. Updates on the epidemiology and risk factors for penile cancer. Translational Andrology and Urology 2017;6:785-90.

5. Hernandez BY, Barnholtz-Sloan J, German RR, et al. Burden of invasive squamous cell carcinoma of the penis in the united states, 1998-2003. Cancer 2008;113:2883-91.

6. Martins FE, Rodrigues RN, Lopes TM. Organ-preserving surgery for penile carcinoma. Adv Urol 2008:634216.

7. McDougal WS. Phallic preserving surgery in patients with invasive squamous cell carcinoma of the penis. J Urol 2005;174:2218-20.

8. Mosconi AM, Roila F, Gatta G, et al. Cancer of the penis. Crit Rev Oncol Hematol 2005;53:165-77.

9. Pietrzak P, Corbishley C, Watkin N. Organ-sparing surgery for invasive penile cancer: Early follow-up data. BJU Int 2004;94:1253-7.

10. Maddineni SB, Lau MM, Sangar VK. Identifying the needs of penile cancer sufferers: A systematic review of the quality of life, psychosexual and psychosocial literature in penile cancer. BMC Urol 2009;9:8.

11. Kieffer JM, Djajadiningrat RS, van Muilekom, et al. Quality of life for patients treated for penile cancer. J Urol 2014;192:1105-10.

12. Opjordsmoen S, Fosså SD. Quality of life in patients treated for penile cancer. A followup study. Br J Urol 1994;74:652-7.

13. Romero FR, Romero KR, Mattos, MA, et al. Sexual function after partial penectomy for penile cancer. Urology 2005;66:1292-5.

14. Witty K, Branney P, Evans J, et al. The impact of surgical treatment for penile cancer -patients' perspectives. Eur J Oncol Nurs 2013;17:661-7.

15. Agrawal A, Pai D, Ananthakrishnan N, et al. The histological extent of the local spread of carcinoma of the penis and its therapeutic implications. BJU Int 2000;85:299-301.

16. Minhas S, Kayes $\mathrm{O}$, Hegarty $\mathrm{P}$, et al. What surgical resection margins are required to achieve oncological control in men with primary penile cancer? BJU Int 2005;96:1040-3.

17. Kamel MH, Bissada N, Warford R, et al. Organ sparing surgery for penile cancer: A systematic review. J Urol 2017;198:770-9.

18. Burnett AL. Penile preserving and reconstructive surgery in the management of penile cancer. Nat Rev Urol 2016;13:249-57.

19. Pompeo ACL, Zequi SdC, Pompeo AS. Penile cancer: Organ-sparing surgery. Curr Opin Urol 2015;25:121-8.

20. Philippou P, Shabbir M, Malone P, et al. Conservative surgery for squamous cell carcinoma of the penis: Resection margins and long-term oncological control. J Urol 2012;188:803-8. 
21. Scarberry K, Angermeier KW, Montague D, et al. Outcomes for organ-preserving surgery for penile cancer. Sex Med 2015;3:62-6.

22. Gulino G, Sasso F, Palermo G, et al. Sexual outcomes after organ potency-sparing surgery and glans reconstruction in patients with penile carcinoma. Indian J Urol 2013;29:119-23.

23. Morelli G, Pagni R, Mariani C, et al. Glansectomy with split-thickness skin graft for the treatment of penile carcinoma. Int J Impot Res 2009;21:311-4.

24. Sansalone S, Silvani M, Leonardi R, et al. Sexual outcomes after partial penectomy for penile cancer: Results from a multi-institutional study. Asian J Androl 2017;19:57-61.

25. Sedigh O, Falcone M, Ceruti C, et al. Sexual function after surgical treatment for penile cancer: Which organ-sparing approach gives the best results? Can Urol Assoc $J$ 2015;9:E423-7.

26. Djajadiningrat RS, van Werkhoven E, Meinhardt W, et al. Penile sparing surgery for penile cancer-does it affect survival? J Urol 2014;192:120-5.

27. Leijte JAP, Kirrander P, Antonini N, et al. Recurrence patterns of squamous cell carcinoma of the penis: Recommendations for follow-up based on a two-centre analysis of 700 patients. Eur Urol 2008;54:161-8.

28. Veeratterapillay R, Sahadevan K, Aluru P, et al. Organ-preserving surgery for penile cancer: Description of techniques and surgical outcomes. BJU Int 2012;110:1792-5.

29. Lont AP, Gallee MPW, Meinhardt W, et al. Penis conserving treatment for T1 and T2 penile carcinoma: Clinical implications of a local recurrence. J Urol 2006;176:575-80.

30. Feldman AS, McDougal WS. Long-term outcome of excisional organ sparing surgery for carcinoma of the penis. J Urol 2011;186:1303-7.

31. Baumgarten A, Chipollini J, Yan S, et al. Penile sparing surgery for penile cancer: A multicenter international retrospective cohort. J Urol 2018;199:1233-7.

32. O'Kelly F, Lonergan P, Lundon D, et al. A prospective study of total glans resurfacing for localized penile cancer to maximize oncologic and functional outcomes in a tertiary referral network. J Urol 2017;197:1258-63.

33. Shabbir M, Muneer A, Kalsi J, et al. Glans resurfacing for the treatment of carcinoma in situ of the penis: Surgical technique and outcomes. Eur Urol 2011;59:142-7.

34. Mahmud A, Qu X, Yip D, et al. The patterns of practice and outcomes of penile cancer in ontario. Clin Oncol (R Coll Radiol) 2017;29:239-47.

35. Parnham AS, Albersen M, Sahdev V, et al. Glansectomy and split-thickness skin graft for penile cancer. Eur Urol 2018;73:284-9.

36. O'Kane HF, Pahuja A, Ho KJ, et al. Outcome of glansectomy and skin grafting in the management of penile cancer. Adv Urol 2011;240824.

37. Smith Y, Hadway P, Biedrzycki O, et al. Reconstructive surgery for invasive squamous carcinoma of the glans penis. Eur Urol 2007;52:1179-85.

38. Albersen M, Parnham A, Joniau S, et al. Predictive factors for local recurrence after glansectomy and neoglans reconstruction for penile squamous cell carcinoma. Urol Oncol 2018;36:141-6.

39. Lindner AK, Schachtner G, Steiner E, et al. Organ-sparing surgery of penile cancer: Higher rate of local recurrence yet no impact on overall survival. World J Urol 2019. 
40. Sri D, Sujenthiran A, Lam W, et al. A study into the association between local recurrence rates and surgical resection margins in organ-sparing surgery for penile squamous cell cancer. BJU Int 2018;122:576-82. 


\section{Figures and Tables}

Fig. 1. (A) Stage T1b squamous cell carcinoma of penis; (B) subsequent intraoperative appearance after glansectomy and split thickness skin graft reconstruction of a neo-glans.

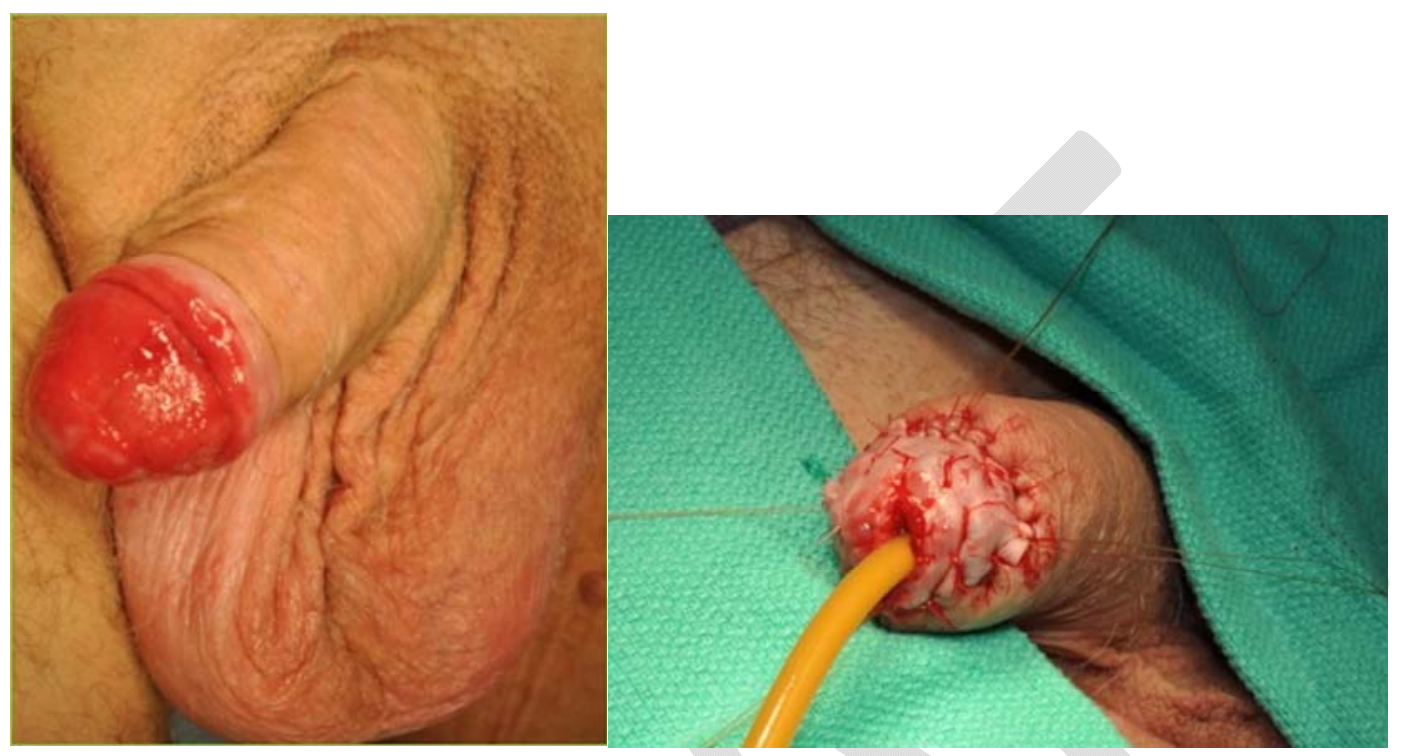

\begin{tabular}{|l|c|}
\hline \multicolumn{2}{|l|}{ Table 1. Baseline patient demographics } \\
\hline Factor & Median (range) or n (\%) \\
\hline Patient age (years) & $62(32-85)$ \\
\hline BMI & $31.8(22.7-42.1)$ \\
\hline Obesity (BMI>30) & $8(66.7 \%)$ \\
\hline Current of former smoker & $8(66.7 \%)$ \\
\hline Absence of pediatric circumcision & $10(83.3 \%)$ \\
\hline Failed prior treatment & $7(58.3 \%)$ \\
\hline Topical & 5 \\
\hline Mohs micrographic surgery & 1 \\
\hline Radiation & 1 \\
\hline
\end{tabular}

BMI: body mass index. 


\begin{tabular}{|l|c|}
\hline \multicolumn{2}{|l|}{ Table 2. Clinical and functional outcomes } \\
\hline Clinical outcome & n (\%) \\
\hline Graft loss & $0(0.0 \%)$ \\
\hline Preserved erectile function & $12(100 \%)$ \\
\hline Standing voiding function & $12(100 \%)$ \\
\hline Acceptable cosmesis & $12(100 \%)$ \\
\hline Patient satisfaction & $12(100 \%)$ \\
\hline Spraying of urinary stream & $2(16.7 \%)$ \\
\hline 90-day SAE & $0(0.0 \%)$ \\
\hline Need for further intervention & $3(25.0 \%)$ \\
\hline Repeat local resection & $1(8.3 \%)$ \\
\hline Radical penectomy & $1(8.3 \%)$ \\
\hline Dilation of meatal stenosis & $1(8.3 \%)$ \\
\hline
\end{tabular}

SAE: serious adverse events.

\begin{tabular}{|l|c|}
\hline \multicolumn{2}{|l|}{ Table 3. Pathologic and oncologic outcomes } \\
\hline Pathological or oncological outcome & n (\%) \\
\hline pT stage & $2(16.7 \%)$ \\
\hline pT0 & $2(16.7 \%)$ \\
\hline pTis & $5(41.7 \%)$ \\
\hline pT1a & $1(8.3 \%)$ \\
\hline pT1b & $2(16.7 \%)$ \\
\hline pT2 & \\
\hline Grade & $2(16.7 \%)$ \\
\hline CIS & $2(16.7 \%)$ \\
\hline 1 & $5(41.7 \%)$ \\
\hline 2 & $1(8.3 \%)$ \\
\hline 3 & $2(16.7 \%)$ \\
\hline Positive margin & $2(16.7 \%)$ \\
\hline Local recurrence & $11(91.7 \%)$ \\
\hline Disease free at last followup & \\
\hline
\end{tabular}

CIS: carcinoma in situ. 